\title{
Investigation of Drag and Churning Losses on Tapered Roller Bearings
}

\author{
Jürgen Liebrecht1,* - Xiaojiang $\mathrm{Si}^{2}$ - Bernd Sauer ${ }^{1}$ - Hubert Schwarze ${ }^{2}$ \\ ${ }^{1}$ University of Kaiserslautern, Institute for Machine Elements, Gears and Transmissions, Germany \\ 2 University of Clausthal-Zellerfeld, Institute of Tribology and Energy Conversion Machinery, Germany
}

Today there are a lot of findings to determine losses caused by contact forces inside roller bearings. But there are also losses in bearings caused by displacement of lubricant. These are known as churning or drag losses. In general the bearing manufacturers give recommendations how to reduce them. The most common solution is the reduction of the oil bath level. Some bearing manufacturers even provide models or empirical equations to calculate the resistance resulting from rolling elements moving through the oil. These models take the operating conditions such as the viscosity of the oil at the operating temperature, oil level, bearing type and rotational speed into consideration. A comparison between calculated and experimental results shows that there is still a deviation because of further effects which are not considered in those analytical models. This paper presents experimental studies and numerical simulations which illustrate the influence of the oil quantity on the total friction torque of tapered roller bearings and identify the resulting losses.

Keywords: tapered roller bearing, churning losses, drag losses, frictional torque, CFD simulation

Highlights
- Method for investigation of drag and churning losses.
- Influence of viscosity, oil quantity and rotational speed.
- $\quad$ Influence of the air content on the drag and churning losses.

\section{INTRODUCTION}

Frictional torque is a significant parameter to describe the efficiency of a roller bearing. It is a result of internal friction which influences the heat generation in the bearing and also determines its losses. The total losses of a bearing can be divided into two parts. The main part is the mechanical friction. It results from contact forces between rolling elements and the runway, the cage and the board contact. The second part of total friction is caused by displacement of lubricant, called churning and drag losses [1]. These hydraulic losses become important because they depend on the operating conditions, and can be as high as the mechanical losses (i.e., [2] to [4]).

To determine the total friction torque bearing manufacturers provide equations (e.g., [5]). In these equations various factors are used to consider the influences of the lubrication. Some of these influencing factors are considered by approximation.

To predict the influence of lubricant displacement on the total friction torque the Institute for Machine Elements, Gears and Transmissions (MEGT) and the Institute of Tribology and Energy Conversion Machinery (ITR) investigate the effects associated with oil lubrication. At the MEGT experimental studies under different test conditions have been carried out. For numerical analysis and description of fluid effects ITR used CFD simulation (i.e., [6] and [7]). The research focus is on axially loaded bearings with a vertical axis of rotation. This concept provides symmetrical operating conditions with a view to uniform lubricant distribution in the bearing. Furthermore symmetrical construction enables the simplification of the simulation model so that only a section of the roller bearing can be considered in the simulation.

Experimental studies focused on the influences of viscosity, cage geometry, bearing type, rotational speed and especially on different oil levels. Furthermore the experimental work includes research of the influence of oil foaming in the lubricant and its effect on the viscosity.

ITR used simulations to illustrate and to understand the significant effects and the fluid flow inside the bearing. Simulations include only-fluidflow as well as two-phase flow. In this paper the first results of experimental studies and numerical simulations are presented.

\section{TEST CONDITIONS}

\subsection{Test Rig}

Conventional test rigs used to measure the total friction torque of bearings usually have a horizontal 

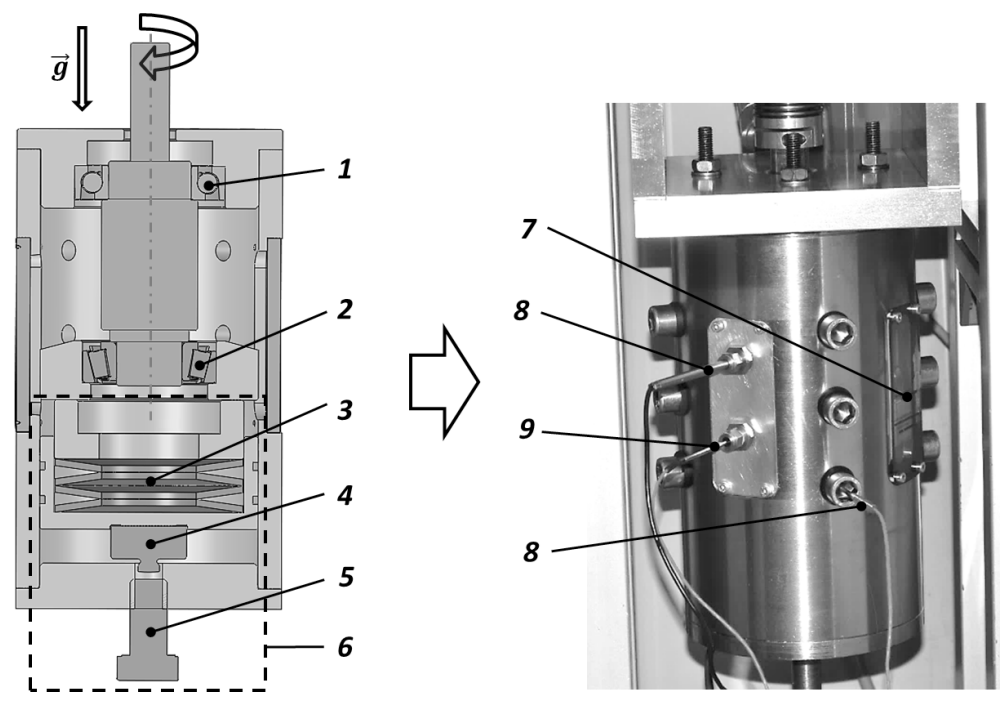

Fig. 1. Sectional view and side view of the bearing test unit (1- support bearing (7210); 2- test bearing (32208); 3- disc springs; 4- force sensor; 5- axial load bolt; 6- axial load unit; 7-vision panel; 8- temp. sensors oil bath; 9- temp. sensor test bearing)

orientated axis of rotation. The test rig used for the experimental studies is presented in Fig. 1. It has a vertical orientated shaft. The reason for using this concept is the equal load distribution and lubrication of the test bearing.

The concept involves the use of a test and a support bearing. The test bearing is the tapered roller bearing 32208. An angular contact ball bearing 7210 made of ceramics $\left(\mathrm{ZrO}_{2}\right)$ is used as a support bearing. The reason for the use of a ceramic bearing is its low friction so that the use of torque measuring sensors with a small range is possible. Furthermore the resolutions of the drag and churning losses have a higher accuracy. Measurements with two support bearings at once might be used to determine their friction torque and for calculating the friction torque of the test bearings. The bearings are mounted in $\mathrm{x}$-arrangement in a test cylinder. The load application onto the bearing arrangement is done by a screw which pushes a force sensor and disk springs against the bearings. To observe the flow around the bearing four vision panels are attached around the test cylinder. For continuous monitoring of operating conditions sensors for measurement of the speed and temperature of the oil and the bearing's outer ring are used. There are two sensors for measurements of the oil temperature above and below the test bearing. For the application of the rotational speed an electrical engine is available which can be driven up to $10,000 \mathrm{rpm}$. To capture the drag losses a torque sensor is mounted between the engine shaft and the test shaft via couplings. Its measuring range is $M=5 \mathrm{Nm}$. The accuracy class of the sensor is
0.5. In this setup the required drive torque corresponds to the total friction torque of the bearing arrangement and is measured by the sensor.

The use of tapered roller bearings in oil bath lubrication involves a pumping effect (i.e., [8] and [9]). This effect is caused by the internal design of the bearing type. The experiment's configuration and bearing arrangement affects the oil flow upwards against gravity (Fig. 2). To provide a constant oil flow rate during the test, the test bearing housing has been modified. There is a slope and few grooves distributed

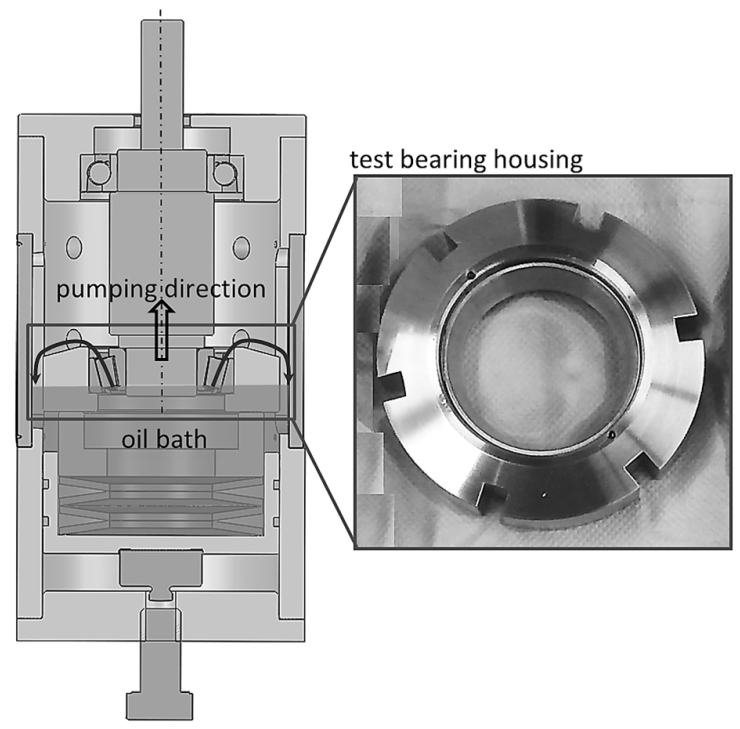

Fig. 2. Modified test bearing housing for compensation of pump effect 
around the circumference through which the oil flow back.

\subsection{Experimental Approach}

Important influences on the total friction torque of a bearing are rotational speed, viscosity of the lubricant, load and oil bath level. The losses caused by the displacement of the lubricant can be regarded as independent of load. That is why the load is kept constant during the experimental studies. The oil level, viscosity and speed represent close-coupled parameters. A higher speed and load causes an increase of the oil and bearing temperature. That usually results in a lower oil viscosity and also lower drag and churning losses. To investigate the hydraulic losses resulting from the rotational speed or the oil level constant boundary conditions were defined. Fig. 3 presents the fully flooded and half flooded test bearing. Experiments with minimal quantity lubrication or injection lubrication provide the results which are used to determine the drag and churning losses. Those are the total friction torque differences between the mentioned oil levels.
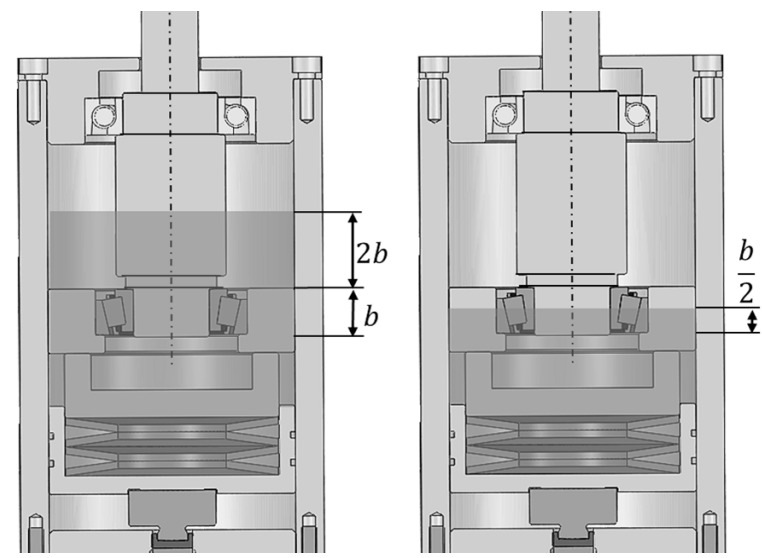

Fig. 3. Different oil bath levels

The oil level of the fully flooded bearing is as high as three times the bearing width. The difference between the total friction torque of the test bearing in flooded condition and the friction torque in the case of minimum quantity lubrication is caused by the hydraulic losses. For the validation of simulation models a speed range from $n=500$ to $6300 \mathrm{rpm}$ and a constant oil temperature of $T=60{ }^{\circ} \mathrm{C}$ were defined. Furthermore two reference oils were selected for the experimental studies. Both are mineral oils and unalloyed, their characteristics and viscosity depending on the temperature are presented in Fig. 4.

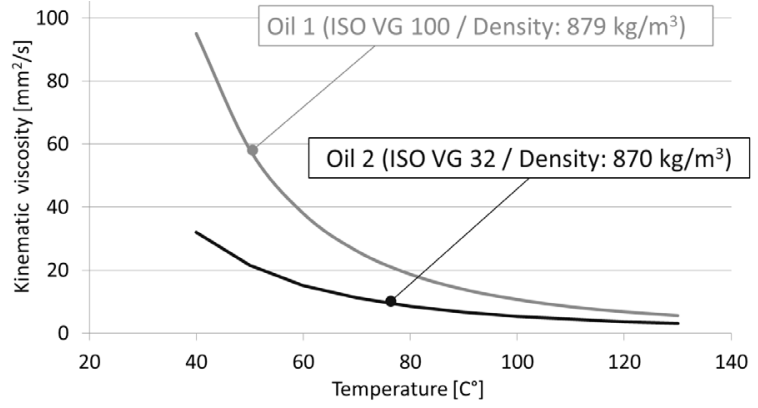

Fig. 4. Effect of the temperature on the viscosity of the test oils

Constant operating conditions are the prerequisite for constructive experimental studies. Their definition is also expedient with a view to theoretical investigation. The calculations of hydraulic losses by means of CFD simulations are connected to an enormous computational effort and require long calculation times. That is why only a very short time interval may be considered as part of the simulation and the parameters that affect the oil temperature or the oil viscosity must be predetermined.

The first step before the measurements is the runin period. This run-in ends after 100,000 revolutions and is used for heating up the test rig. The adjustment of the operating temperature requires, in particular at low speeds, a selective heating of the oil. Higher speeds cause higher friction and amount of heat that dissipates into the oil. Consequently, operating conditions at higher speeds require cooling of the oil. To set the operating temperature without the use of an oil unit, a testing strategy which already proved effectively in [10] was chosen. For heating or cooling the oil and setting the oil viscosity different speed steps are driven successively. This way at low speeds the oil is always heated over the needed temperature and the operating point can be measured during the cooling phase. At higher speeds the oil is always cooled below the needed temperature and measurement is carried out during the heating (see Fig. 5). This procedure is repeated several times to provide a higher statistical certainty.

The experimental determination of the drag and churning losses is enabled by varying the oil level. This requires tests with a minimum amount of oil. The friction torque which is determined in this way provides the reference for assessing the drag and churning losses.

Due to the forming of a lubricating film, the different lubrication states must be comparable. So it is not possible to do tests without lubrication at all. To reproduce the condition of the forming of a lubricating film in experiment the test bearing is oil 
jet lubricated. Fig. 6 shows that the lubrication occurs not continuous but stepwise. Between these steps the friction torque decreases, this effect is known as starvation. It decreases until the next oil injection occurs. For each measurement point the same oil volume of $1 \mathrm{ml}$ is injected. Those maxima represent the reference oil level which are used to determine the hydraulic losses. In order to provide uniform operating conditions as described above, the injected oil is heated up to $T=60^{\circ} \mathrm{C}$.

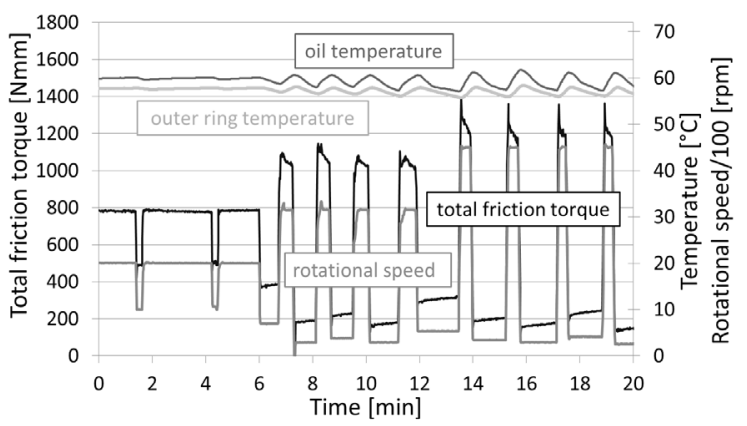

Fig. 5. Adjustment of operating temperature

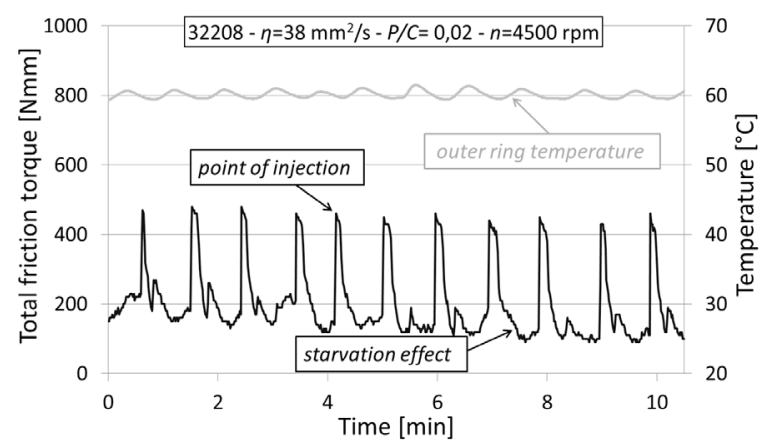

Fig. 6. Effect of the oil jet lubrication on the total friction torque

The temperature of the outer ring in oil bath lubrication test bearing corresponds to the oil temperature, like shown in Fig. 5. For this reason the outer ring is heated up with hot air to an appropriate temperature level $\left(58{ }^{\circ} \mathrm{C} \leq T_{o i l} \leq 60{ }^{\circ} \mathrm{C}\right)$ before injection of the oil. According to rolling bearing manufacturer information the temperature of the inner ring is usually about $5^{\circ} \mathrm{C} \leq T_{i r} \leq 10^{\circ} \mathrm{C}$ higher than the outer ring temperature [11]. This temperature was not measured in the experiment. Due to this the operating conditions are only adjusted by the heating up of the outer ring.

The lubrication of the supporting bearing is carried out periodically to avoid damage. It is oil jet lubricated. At the time of lubrication there is a shorttime increase in the total friction torque after that it drops to a constant value so that the measurement is not affected by the lubrication of the test bearing.

\subsection{Simulation}

Hydraulic losses in roller bearings can be divided in two main components. The first one is caused by the movement of the rolling elements and the cage in the lubricant. It results from the shear stress $\tau$ by the lubricant friction and the compressive stress $p$ on the rolling elements. Those stresses are exerted contrary to the rolling direction of the rolling elements and form the drag torque which depends on the bearing diameter. This drag torque corresponds to the drag losses. The second component of the hydraulic losses is the churning torque. This is mainly caused by the shearing of the oil at the bearing surfaces during dipping into the oil bath. Those surfaces are rolling elements end, cage surface, cage ends, cage pockets and lips [12]. This churning torque corresponds to the churning losses.

To solve fluid mechanical tasks calculation tools are required. One way to calculate the hydraulic losses are CFD simulations [13]. The solution for complex flow distributions inside a bearing is based on the volume-of-fluid method (VOF). The main problem here is the flow area, which is three-dimensional, unsteady and two-phase. This means oil and air have to be considered. For simulation of flow CFX software packages with integrated modules for the modelling and evaluation of results are used. For flow calculation a 3-D contour adapted computational grid is used. The free flow area in the test bearing and the shaft are considered in the grid. To provide a high calculation accuracy hexahedron grid cells are used. For modeling the motion of the rolling bearing elements a Frame Change Model is applied which is known as transient rotor stator (TRS). This solution provides accurate models to describe the motion between moving and stationary domains. The disadvantage of this method is that large computer resources are required. The applied model considers the rotation of the rolling elements around its own axis and also the rotation around the symmetry axis of the bearing at the same time. It also considers the different speeds between the rolling elements including cage and inner ring. The outer ring is modeled as the stationary domain.

The computational grid of the simulation model and its size influence the quality of the calculation results and also the computational time. Fig. 8 shows the three-dimensional computational grid of the entire model which is used for the simulation. That computational grid has approximately 2.5 million 

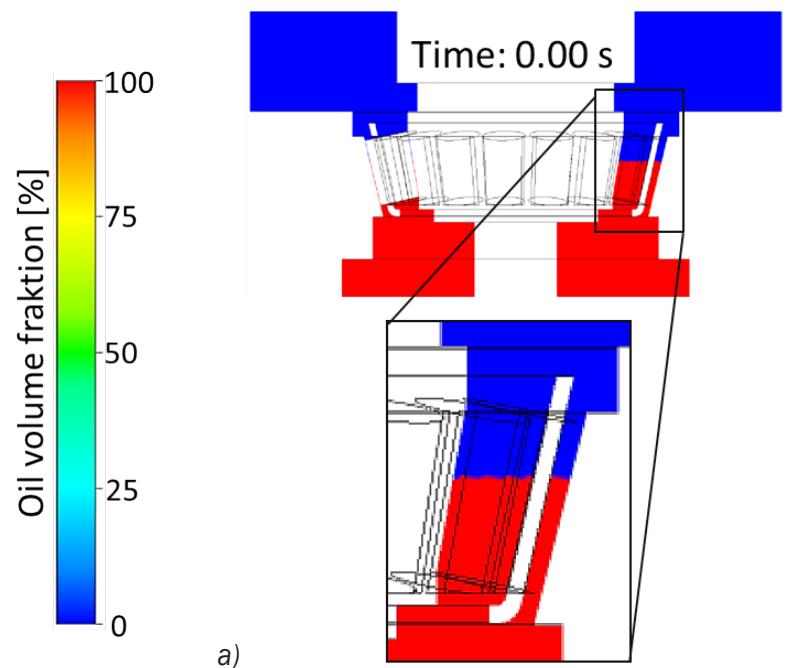

b)

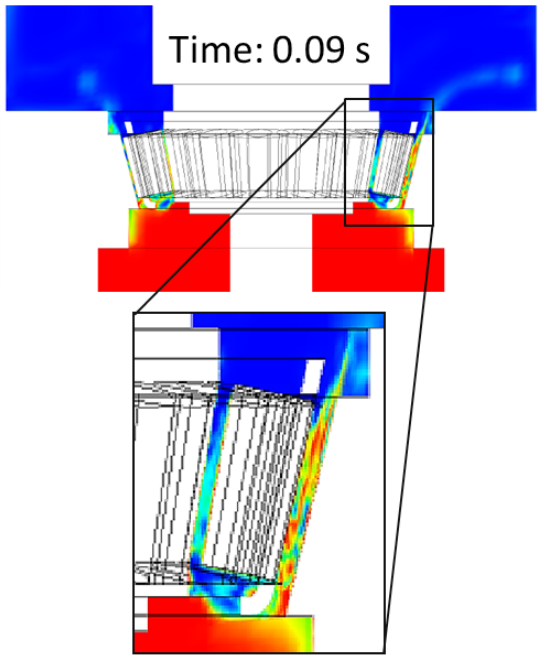

Fig. 7. Instantaneous oil volume fraction in a tapered roller bearing at a) $0 \mathrm{~s}$ and b) $0.09 \mathrm{~s}$

cells. For a precise calculation of the flow inside the tapered roller bearing the grid in this area is much finer than the grid in the space below and above the test bearing.

When evaluating the CFD simulation a twodimensional visualization of the oil distribution in the test bearing is available. With this visualization, information on flow phenomena may be obtained. Fig. 7 shows an example of the oil distribution in the cross section of the simulation model for the tapered roller bearing in a half-flooded test bearing. In the figure two discrete time points are presented. The figures provide information on the oil flow caused by the rotation of the tapered roller bearing. The oil is displaced within a very short timeframe by the interaction of the rolling elements, the cage and the internal geometry of the tapered roller bearing in the testing room above the test bearing.

\section{EXPERIMENTAL AND SIMULATION RESULTS}

\subsection{Influence of the Oil Level and Viscosity}

Fig. 9 illustrates the influence of the oil level on the hydraulic losses of tested tapered roller bearing 32208 at a constant operating temperature of $T=60{ }^{\circ} \mathrm{C}$. The results for a fully-flooded $(h=3 b)$ and a halfflooded ( $h=0.5 b)$ test bearing for both test oils are presented. As expected Oil 1 causes higher hydraulic losses, due to its higher viscosity. The rise of rotational speed effects a faster displacement of the lubricant and results in higher losses as well. Consequently, the speed is a significant parameter for reducing the losses. The influence of the oil bath level is also

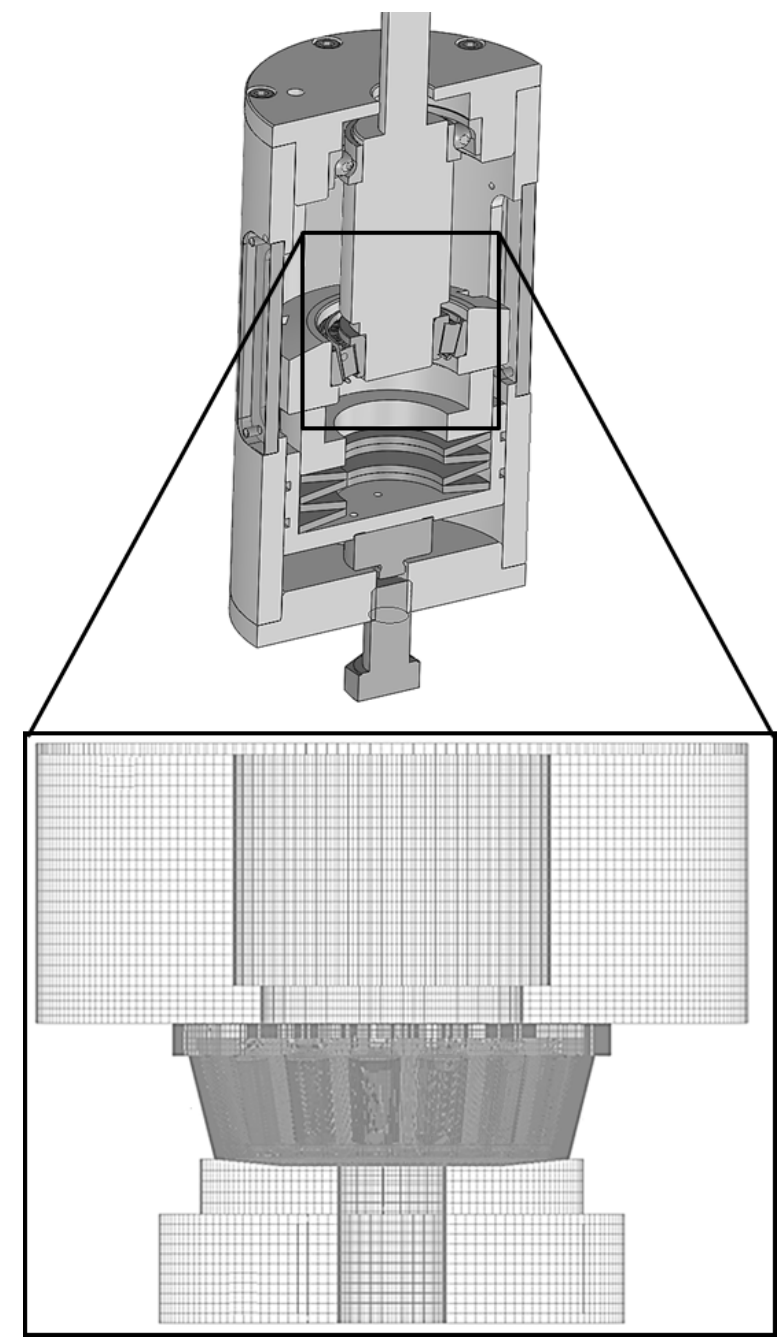

Fig. 8. Mesh modelling of tapered roller bearing for CFDsimulation of drag and churning losses 


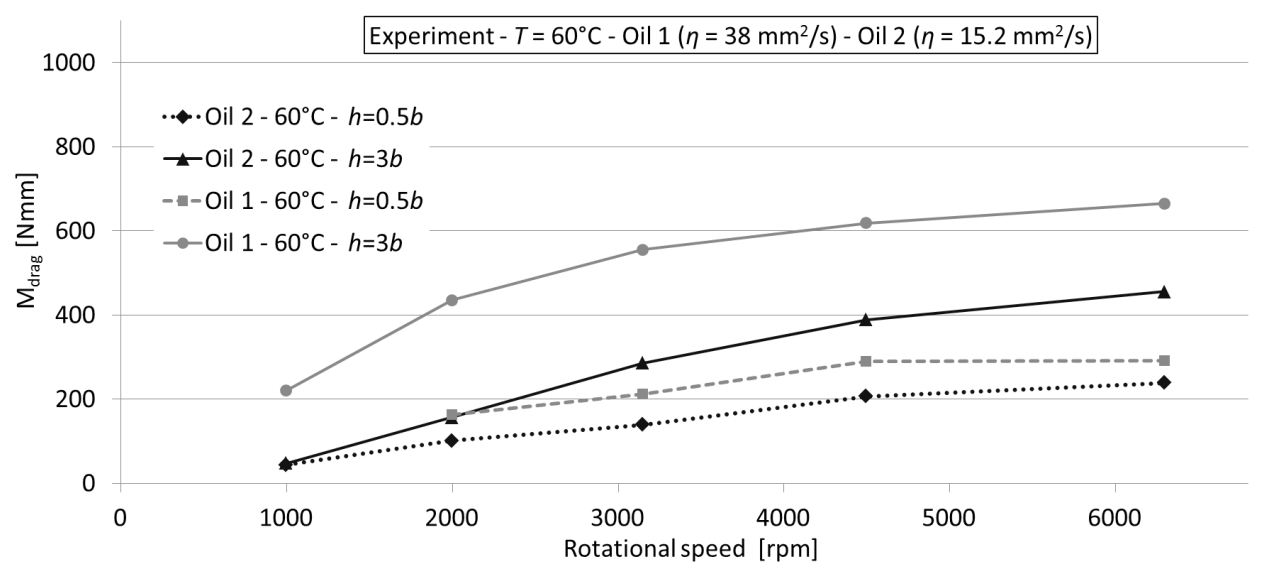

Fig. 9. Influence of the oil level and rotation speed on the hydraulic losses of a tapered roller bearing 32208 (operating temperature, $\mathrm{T}=60^{\circ} \mathrm{C}$ )

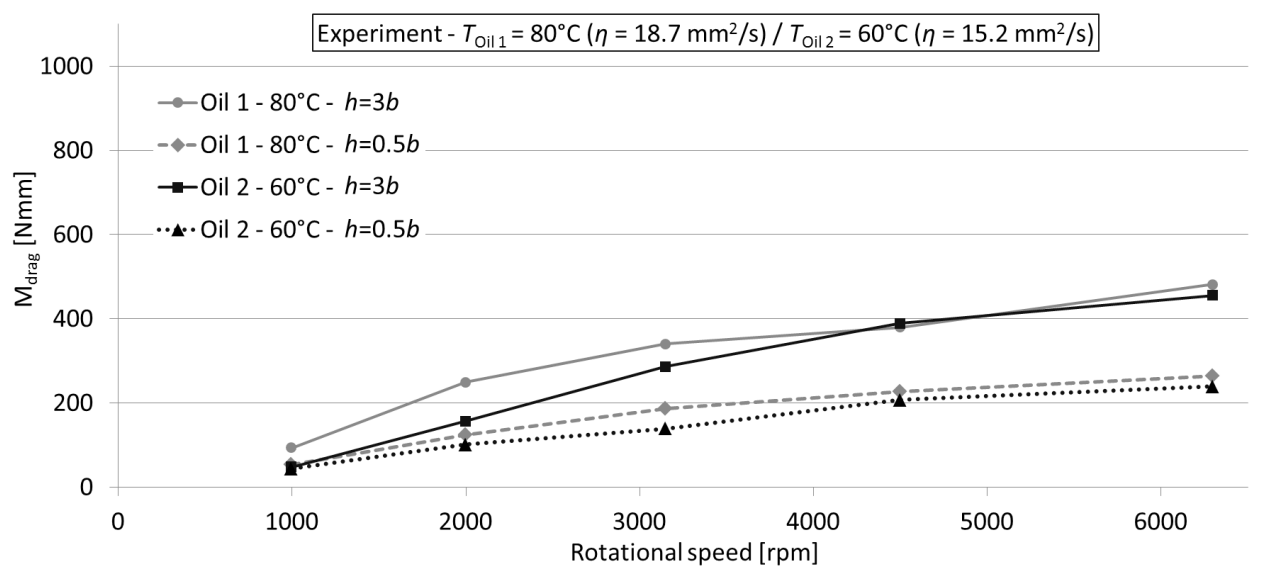

Fig. 10. Comparison of test oils at a similar operating point with a view to viscosity (hydraulic losses of a tapered roller bearing 32208)

explicit. Especially the results from experiment with Oil 1 present the clear difference of lubricant losses. To get a similar viscosity of the test oils different operating temperatures were set up. Oil 2 was heated up to $T_{\mathrm{Oil} 2}=60^{\circ} \mathrm{C}$, Oil 1 to $T_{\text {Oil } 1}=80^{\circ} \mathrm{C}$. That way the kinematic viscosity were reduced to $\eta=18.7 \mathrm{~mm}^{2} / \mathrm{s}$ for Oil 1 and $\eta=15.2 \mathrm{~mm}^{2} / \mathrm{s}$ for Oil 2. Fig. 10 illustrates that the hydraulic losses (drag and churning losses) are similar in size when specifying an insignificant viscosity difference. Those results are showing the drag and churning losses are independent of the oil but depend on the viscosity.

The advantage of the CFD simulation in comparison to the experiment is the opportunity to consider the elements of the test bearing with regard to drag and churning losses individually. Table 1 shows the assignment of the losses to the elements of the test bearing. The results make clear that the main part of the losses is caused by the rolling elements, outer and inner ring. In case of rolling elements the pressure on

Table 1. Subdivision of drag and churning losses in tapered roller bearing 32208 for different rotational speeds in \%

\begin{tabular}{lcccc}
\hline Rolling bearing element & Classification & $2000[\mathrm{rpm}]$ & $4500[\mathrm{rpm}]$ & 6300 [rpm] \\
\hline Rolling elements-raceway & inertial & 45.11 & 45.40 & 45.00 \\
\hline Rolling elements-raceway & viscous & 9.09 & 9.10 & 8.90 \\
\hline Rolling elements-face & viscous & 0.54 & 0.55 & 0.61 \\
\hline Cage & viscous & 0.73 & 0.95 & 0.92 \\
\hline Inner \& Outer ring & viscous & 36.43 & 37.53 & 37.39 \\
\hline
\end{tabular}


the raceway due to density (drag losses) causes much higher losses than the shear stress of the lubricant (churning losses). The rest of the hydraulic losses which are not mentioned in Table 1 arise outside of the tapered roller bearing.

\subsection{Influence of the Inner Geometry}

To investigate the influence of the inner geometry of the bearing on the hydraulic losses experiments with a second tapered roller bearing 32208 produced by another manufacturer were carried out. The cone angle and the number of rolling elements of both bearings are identical. Because of standardization the size and the geometry of inner and outer ring are also the same. The only difference between the test bearings is the length of the rolling elements and consequently the length of the cage. The differences are presented in Table 2.

Table 2. Main parameters of the test bearings

\begin{tabular}{lcc}
\hline Test bearing & 1 & 2 \\
\hline Length rol. elements [mm] & $\approx 16$ & $\approx 17$ \\
\hline Length cage [mm] & $\approx 22$ & $\approx 23$ \\
\hline Number of rol. elements & 17 & 17 \\
\hline
\end{tabular}

Fig. 11 illustrates the experimental results. The losses which have been measured on the test bearings have a similar size. In this case geometric differences influence the losses insignificantly. However at higher speed levels the differences such as larger surface area from rolling elements and a longer cage become noticeable because test bearing 2 causes higher drag and churning losses. But in this case the accuracy of the sensor must also be considered with regard to the results.

\subsection{Simulation Results and Comparison}

The experiments are used to validate the simulation model, presented in Chapter 1.3. Fig. 12 illustrates a comparison of simulation and calculation results. The latter is provided by the SKF-model to calculate the drag and churning losses. The calculation requires only the kinematic viscosity at the operating temperature to consider the lubricant. In opposite to the simulation there is no possibility to consider the changing density. Due to this fact a single-phase simulation was performed to determine drag and churning losses for oil level $h_{\text {oil }}=3 b$. In Fig. 12 results of simulation and calculation of a half-flooded ( $h_{\text {oil }}=0.5 b$ ) and a fullyflooded $\left(h_{\text {oil }}=3 b\right)$ tapered roller bearing 32208 at operating temperature of $60{ }^{\circ} \mathrm{C}$ are compared. There is a difference between calculated and simulated results for the higher oil bath level. One explanation is the factor which considers vertical shaft orientation. In the case of an oil bath level $h_{\text {oil }} \geq 1 b$ it always amounts to 1 . For the low oil bath level the correlation between calculation and simulation is much better.

The shaft rotation induces a two phase mixture of oil and air and the air volume rises with rotational speed. This effect can be considered in a single-phase simulation by changing the dynamic viscosity. In general liquid and gas can be observed as a fluid [14]. Its properties correspond to the parts by volume of both components:

$$
\mu=\mu_{f} c+\mu_{g}(1-c) .
$$

The factors $c$ und $\mu$ represent the volume share and the dynamic viscosity at the operating point. Indices $f$ and $g$ stand for fluid (lubricant) and gas (air). Volume share $c$ can be calculated with Eq. (2) by using the densities $\rho_{f}$ and $\rho_{g}$ of oil and air.

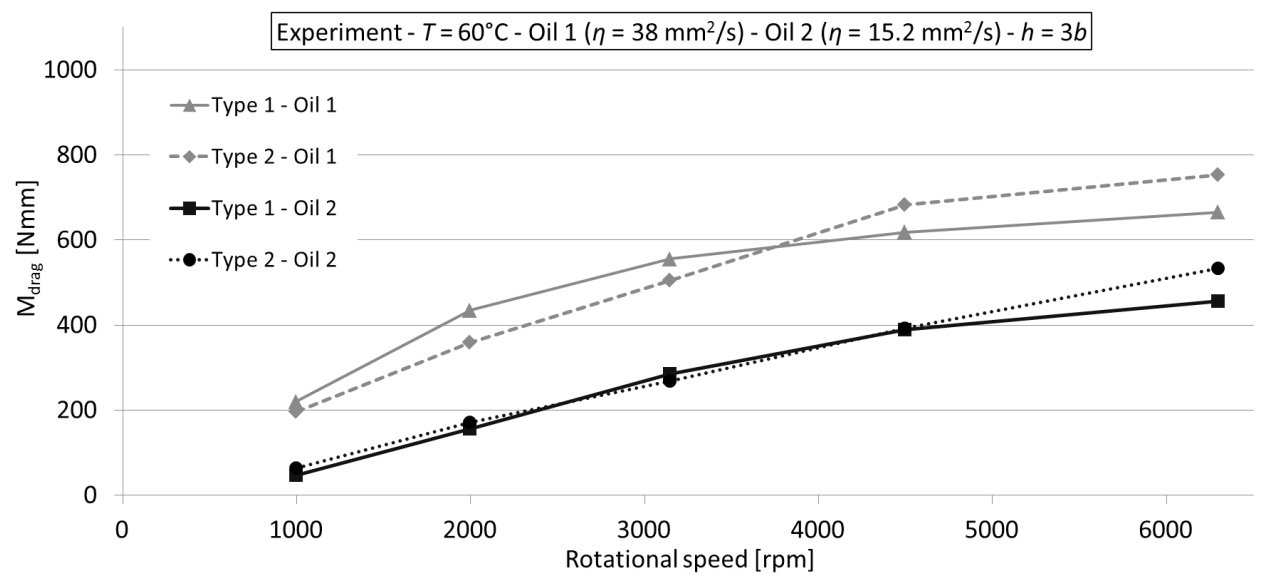

Fig. 11. Influence of the inner geometry on the drag and churning losses 


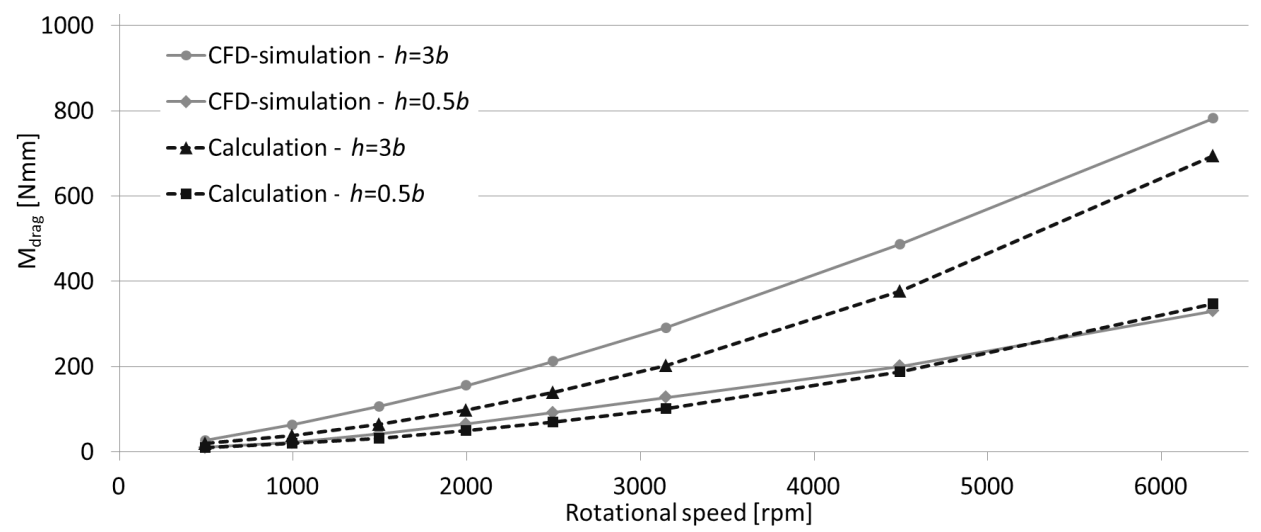

Fig. 12. Comparison of CFD-simulation and calculation results (SKF-model)

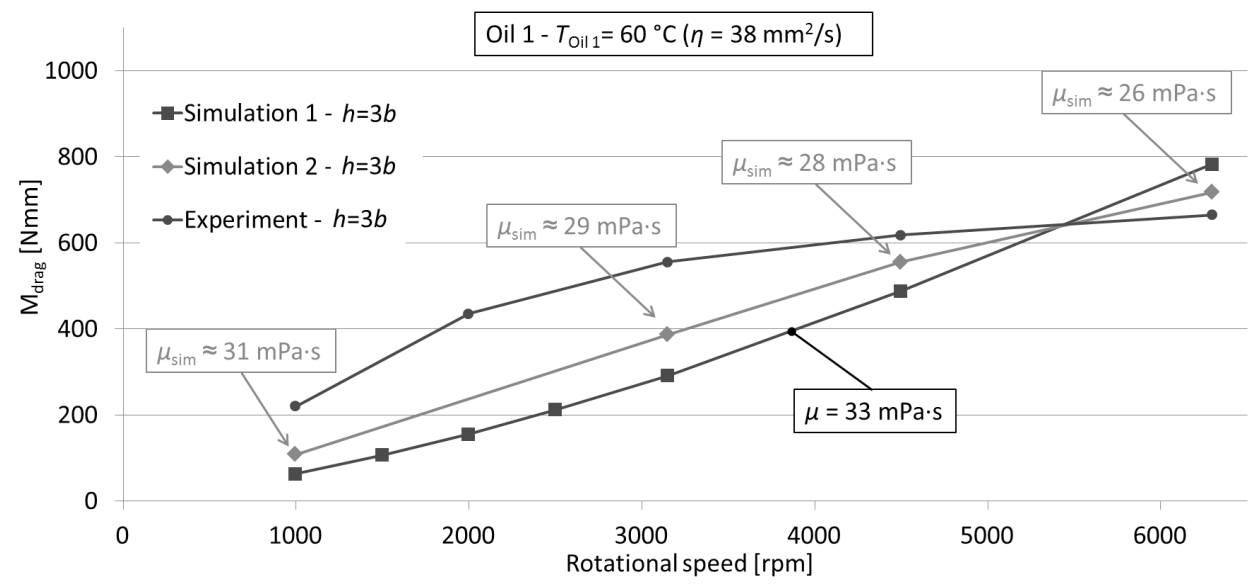

Fig. 13. Influence of the foaming of oil on the dynamic viscosity and simulation results

$$
\rho=\rho_{f} c+\rho_{g}(1-c) .
$$

For this purpose, the changes in the weight of a defined oil volume at different speeds have to be measured. The approximation of air density may stay disregarded, as well as the dynamic viscosity in Eq. (1). Multiplication of the volume share with the dynamic viscosity provides the modified dynamic viscosity for the simulation. The shares of the dynamic viscosity which are used in simulation to consider the foaming of oil are shown in Table 3.

Fig. 13 presents the simulation results using dynamic viscosities considering the foaming of oil. They are compared to the simulation results already presented in Fig. 12 and experimental results. The hydraulic losses which have been calculated by considering the modified viscosity more accurately conform to the experimental results. Especially the curve progression has changed to a better fit. Its tendency corresponds to the curve progression of the experimental values. The differences between simulation and experiment may be caused by the way of determining the dynamic viscosity.

Table 3. Viscosity of test Oil 1 in consideration of air content (Volume Oil $\approx 24 \mathrm{ml}$, Weight $\approx 20.8 \mathrm{~g}, T_{\text {oil }}=60^{\circ} \mathrm{C}, \eta=38 \mathrm{~mm}^{2} / \mathrm{s}$ )

\begin{tabular}{ccc}
\hline Speed [rpm] & $\Delta$ Weight Oil [g] & Viscosity share [\%] \\
\hline 0 & 0 & 100 \\
\hline 1000 & -0.93 & 95 \\
\hline 2000 & -1.68 & 92 \\
\hline 3150 & -2.38 & 88 \\
\hline 4500 & -3.14 & 84 \\
\hline 6300 & -4.16 & 80 \\
\hline
\end{tabular}

Further simulation results are provided in Fig. 14. It represents simulation and experimental results with test Oil 2. As shown in the figure the experiment corresponds to the simulation. The differences between measured and calculated losses are insignificant. These simulations consider the foaming of the oil as well as the simulations with test Oil 1 (Table 4). 


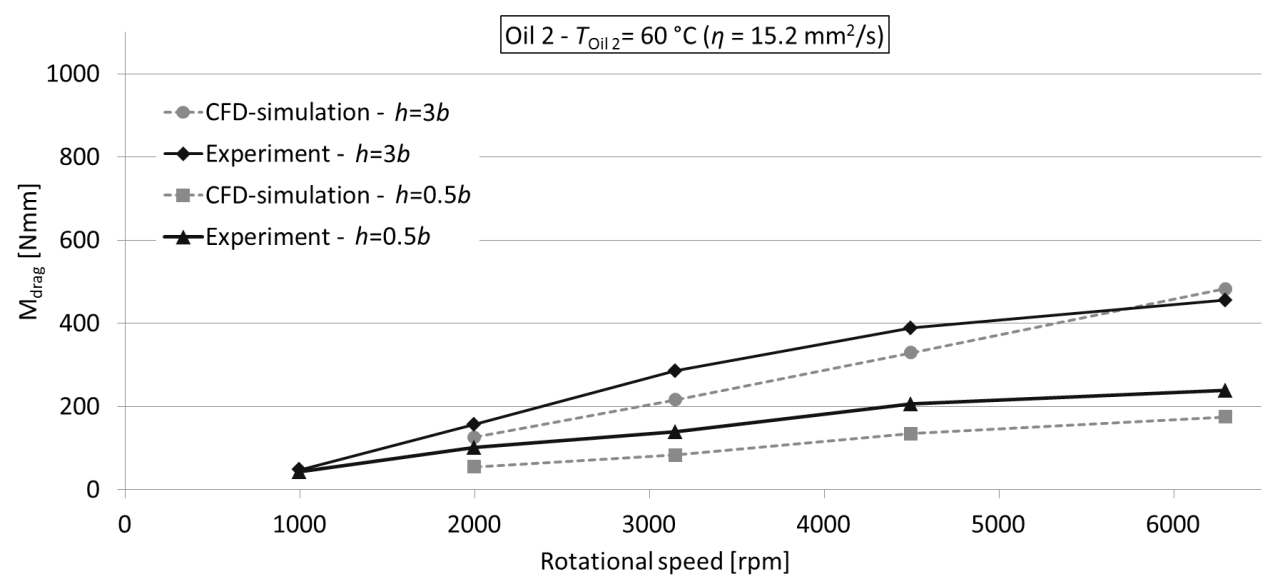

Fig. 14. Comparison of experimental and simulation results for test 0il 2

Table 4. Viscosity of test Oil 2 in consideration of air content (Volume Oil $\approx 24 \mathrm{ml}$, Weight $\approx 20.7 \mathrm{~g}, T_{\text {oil }}=60^{\circ} \mathrm{C}, \eta=15.2 \mathrm{~mm}^{2} / \mathrm{s}$ )

\begin{tabular}{ccc}
\hline Speed [rpm] & $\Delta$ Weight Oil $[\mathrm{g}]$ & Viscosity share [\%] \\
\hline 0 & 0 & 100 \\
\hline 1000 & -1.37 & 93 \\
\hline 2000 & -2.35 & 89 \\
\hline 3150 & -3.41 & 84 \\
\hline 4500 & -4.03 & 81 \\
\hline 6300 & -4.62 & 78 \\
\hline
\end{tabular}

\section{CONCLUSION}

The first results presented in this paper give an overview on the experimental and theoretical investigations of drag and churning losses in tapered roller bearings. They clearly indicate that rotational speed, oil viscosity and especially the oil level affect the drag and churning losses of this bearing type significantly. Furthermore CFD-simulations illustrate the accuracy of available methods to calculate the drag and churning losses. Simulations considering modified dynamic viscosity caused by oil foaming correspond better to experiment. Even the tendency of curve progression is approximated. For better results enhanced viscosity measurement needs to be implemented.

Next steps will be to compile a generally accepted analytical model to calculate the drag and churning losses. This model will include tapered roller bearings with a vertical shaft. Also experiments and simulations with other bearing types, such as deep groove ball bearings and angular contact ball bearings will be carried out. Furthermore it is possible to influence the air content in the lubricant by the use of antifoam additives (foam inhibitors). To investigate the effects of such additives with regard to drag and churning losses further experiments are planned.

\section{ACKNOWLEDGMENT}

The results presented in that paper are prepared in the framework of a project financed by the German Research Association (DFG-SA898/12-1 and DFGSCHW826/9-1).

\section{REFERENCES}

[1] Pradeep, K.G. (1984). Advanced Dynamics of Rolling Elements. Springer-Verlag, New York.

[2] Koryciak, J. (2007). Einfluss der Ölmenge auf das Reibmoment von Wälzlagern mit Linienberührung. PhD Thesis. Lehrstuhl für Konstruktionstechnik der Ruhr-Universität Bochum, Bochum.

[3] Aul, V., Kiekbusch, T., Marquart, M., Sauer, B. (2010). Experimentelle und Simulative Ermittlung von Reibmomenten in Wälzlagern. Fachtagung der Gesellschaft für Tribologie und Schmierung, Göttingen, 2010, S. 30/1-17.

[4] Aul, V., Kiekbusch, T., Marquart, M., Sauer, B. (2011). Experimentelle und simulative Ermittlung von Reibmomenten in Wälzlagern bei Minimalmengenschmierung. Fachtagung der Gesellschaft für Tribologie und Schmierung Göttingen, 2011, S. 51/1-16

[5] SKF Gruppe. Wälzlager. Wälzlager-Katalog. PUB BU/P1 10000/2 DE. 2014, S. 99-114.

[6] Becker, D., Schwarze, H., Brenner, G. (2009). Verbesserte Simulation der Reibungs- und Verschleissverhältnisse hochbelasteter Tribosysteme. ATZ / MTZ - Konferenz Reibungsminimierung, Esslingen.

[7] Brenner, G., Al-Zoubi, A., Mukinovic, M., Schwarze, H., Swoboda, S. (2007). Numerical simulation of surface roughness effects in laminar lubrication using the LatticeBoltzmann method. Journal of Tribology, vol. 129, no. 3, p. 603-610, DOI:10.1115/1.2736452. 
[8] Leibensperger, R.L. (1972). Analysis of the flow of oil through a tapered roller bearing. Journal of Lubrication Technologie, vol. 94 no. 2, p. 125-130, D0l:10.1115/1.3451652.

[9] Kazutoshi, T., Masamichi, S., Teruo, H. (1997). Observation of lubricating oil behavior in internal free space of tapered roller bearing. Japanese Journal of Tribology, vol. 42, no. 4, p. 491496.

[10] Liebrecht, J., Si, X., Sauer, B., Schwarze, H. (2014). Untersuchungen von hydraulischen verlusten an Kegelrollenlagern. Fachtagung der Gesellschaft für Tribologie und Schmierung, Göttingen, 2014, S. 22/1-11.
[11] Schaeffler Technologies AG\&Co. KG. Wälzlager. WälzlagerKatalog. August, 2012, S. 110.

[12] Concli, F., Gorla, C. (2012). Computational and experimental analysis of the churning power losses in an industrial planetary speed reducers. WIT Transactions on Engineering, Sciences, vol. 74, p. 287-298, D0l:10.2495/afm120261.

[13] Seebode, F. (2011). Axialer Ölfluss durch Wälzlagerungen. PhD Thesis. Institut für Tribologie und Energiewandlungsmaschinen. TU Clausthal, Clausthal.

[14] Ferziger, H., Peric, M. (2008). Strömungen mit freien Oberflächen. Nummerische Strömungsmechanik. SpringerVerlag Berlin Heidelberg. p. 463-468. 